Published in final edited form as:

Angew Chem Int Ed Engl. 2006 November 20; 45(45): 7622-7626.

\title{
Synthesis of the Southern FGHI Ring System of Azaspiracid-1 and Investigation into the Controlling Elements of C28- and C36- Ketalization*
}

\author{
Xiao-Ti Zhou, Liang Lu, Daniel P. Furkert, Charles E. Wells, and Rich G. Carter \\ Department of Chemistry Oregon State University Corvallis, OR 97331 USA Fax: (+ 1) 541-737 \\ -9496 E-mail: rich.carter@oregonstate.edu
}

\section{Keywords}

aldol reaction; azaspiracids; fused-ring systems; ketalization; natural products

The azaspiracid family of natural products has stimulated significant interest in both the synthetic[1-3] and biological communities[4] due to their complex structural architecture and toxicity (Figure 1). We were initially drawn toward azaspiracid-1 (1) by the C10,C13-bisspiroketal portion of the molecule. Our endeavors have led to a better understanding of the controlling elements behind this structural motif.[1] Herein, we detail our successful construction of the FGHI ring system present in the southern portion of azaspiracid.

Our retrosynthetic strategy for the southern portion of azaspiracid disconnected FGHI ring system 6 at the C34-35 linkage to yield aldehyde 7 and allyl silane 8 (Scheme 1). To establish the correct stereochemistry at C34, this key coupling would need to proceed via a Cramchelated intermediate with aldehyde 7 . The allyl silane portion would be available from the known Myers alkylation product 9.[5] The aldehyde 7 should be accessible from the Andrus aldol adduct 10, which in turn could be constructed from the sultam $\mathbf{1 1}$ and the chloride $\mathbf{1 2}$.

The synthesis of the allyl silane $\mathbf{8}$ is shown in Scheme 2. The Myers alkylation adduct $\mathbf{9}$ was prepared in four steps from the commercially available oxazolidinone 13.[5] Treatment of 9 with methyllithium yielded the methyl ketone 14. Next, conversion of $\mathbf{1 4}$ into the enol triflate followed by palladium-catalyzed coupling gave the allyl silane 15. Removal of the benzyl ether was accomplished by using sodium naphthalenide. Finally, Mitsunobu reaction gave the phthalimide 8 .

Synthesis of the aldehyde fragment 7[6] was accomplished in eight steps (Scheme 3). After monobenzylation of the commercially available dichloride 16, cuprate addition to the known sultam 11, under similar conditions described by Paquette and Boulet,[7] led to generation of the stereocenter at C30 with excellent diastereoselectivity (d.r. > 20:1). Direct reduction of the product to the aldehyde $\mathbf{1 8}$ followed by boron-mediated aldol reaction with the Andrus dioxanone (19)[8] resulted in the adduct 10 again with excellent selectivity (d.r. > 10:1). Ring opening of the lactone $\mathbf{1 0}$ to its methyl ester $\mathbf{2 0}$ followed by CAN oxidative cleavage provided

\footnotetext{
**Financial support was provided by the National Institutes of Health (GM63723). The authors would also like to thank Prof. Max Deinzer (OSU) and Dr. Jeff Morré (OSU) for mass spectral data, Rodger Kohnert (OSU) and Dr. Clemens Anklin (Bruker Biospin) for NMR assistance, Damien L. Kupier (OSU) for his synthetic assistance toward aldehyde 18, David J. Weldon (University of Mississippi) for his early work on the synthesis of 32, and Dr. Roger Hanselmann (Rib-X Pharmaceuticals) for helpful discussions.

Correspondence to: Rich G. Carter.

Supporting information for this article is available on the WWW under http://www.angewandte.org or from the author.
} 
the diol 21. The key [3.2.1] bicyclic ketal moiety could be constructed through ozonolysis of 21 with DMS workup, which induced spontaneous C28-ketal formation. This ketalization process could be driven to completion by the addition of Amberlyst- 15 . Finally, reduction with DIBAL-H proceeded cleanly to give the aldehyde $\mathbf{7}$. The stereochemistry of aldehyde $\mathbf{7}$ was conclusively established through X-ray crystal structure assignment of the 2,4dinitrohydrazone derivative 22.[9]

With the two major subunits in hand, we shifted our focus to their combination (Scheme 4). Treatment of a precooled solution of aldehyde 7 with Lewis acids $\left(\mathrm{TiCl}_{4}\right.$ or $\left.\mathrm{SnCl}_{4}\right)$ followed by the addition of allyl silane $\mathbf{8}$ provided the coupled material as a single diastereomer at C34. We had hypothesized that chelating Lewis acids such as titanium or tin would proceed via the intermediate $\mathbf{2 3}$ to give the desired stereo-chemical outcome (24). We were surprised to find, upon conversion of the intermediate into its Mosher ester 27,[10] that the C34 stereochemistry was in fact that of the undesired isomer. Further support for this assignment can be found in the fact that treatment of 7 with $\mathrm{BF}_{3} \cdot \mathrm{Et}_{2} \mathrm{O}$ (a Lewis acid incapable of proceeding via intermediate 23) also gave alcohol 26, again as a single diastereomer. Despite our considerable efforts, we were unable to devise a viable route to invert the stereochemistry at C34.

It would appear from our efforts that the encumbered nature of alcohol 26 made it impossible to properly install the $\mathrm{C} 34$ stereogenic center. On the basis of this setback, we chose to revise our approach (Scheme 5). Starting from the known PMB-protected ester 28, [11] DIBAL-H reduction, iodination, and Myers alkylation gave 30. Conversion of $\mathbf{3 0}$ into the methyl ketone followed by DDQ deprotection and two-step azide incorporation gave $\mathbf{3 2}$.

For the aldehyde component $\mathbf{3 4}$, selective protection at $\mathrm{C} 32$ was required. Triisopropylsilylation of aldol adduct $\mathbf{1 0}$ did yield the corresponding silyl ether; however, methanolysis of the lactone proved unsuccessful. Fortunately, treatment of $\mathbf{2 0}$ with TIPSOTf and 2,6-lutidine at low temperature gave selectively the C32-OTIPS product 33. None of the corresponding benzyl OTIPS ether was observed. Finally, deprotection with CAN, protection with TMS, and reduction produced the aldehyde $\mathbf{3 4}$.

Next, our efforts returned to the combination of the subunits $\mathbf{3 2}$ and $\mathbf{3 4}$ (Scheme 6). Aldol reaction of ketone $\mathbf{3 2}$ and aldehyde $\mathbf{3 4}$ gave the coupled adduct 35 in excellent yield as a single diastereomer. On the basis of precedent from us and others, $[2 \mathrm{e}, 3 \mathrm{e}, \mathrm{g}]$ we suspected that the C34 stereochemistry was once again incorrect. Fortunately, after removal of the TMS group at C33 and mixed ketal formation at $\mathrm{C} 36$, we were able to cleanly invert the $\mathrm{C} 34$ stereochemistry using Martin's modified Mitsunobu conditions.[12] Staudinger reduction of the azide followed by Teoc protection and cyclization[2e] using $\mathrm{Yb}(\mathrm{OTf})_{3}$ gave the $\mathrm{HI}$ ring system in $\mathbf{3 8}$. The desired stereochemistry at C34 was confirmed through modified Mosher ester analysis.[10] Treatment of 38 with TBAF in THF induced selective removal of the TIPS (C32) and PNB (C34) protecting groups in the presence of the Teoc moiety. With only alkene cleavage at $\mathrm{C} 28$ and [3.3.1] bicyclic ketal formation remaining, we believed that the completion of the FGHI ring system was within reach. We were surprised to find that despite considerable experimentation, we consistently observed degradation of the material during ozonolysis. Small amounts of a minor product could be isolated for which the spectral data was supportive of furan structure 42, which presumably formed via the enol ether intermediate 41.

Thwarted by the unexpected furan formation, we reexamined the ordering of cyclization events (Scheme 7). Starting from the C34 inversion product 37, C28 alkene dihydroxylation and cleavage yielded the ketone 43. Removal of the TIPS ether at $\mathrm{C} 32$ as well as the $p$-nitrobenzoate group at $\mathrm{C} 34$ with TBAF yielded the diol $\mathbf{4 4}$. While non-alcoholic solvents proved problematic in the formation of the [3.3.1] bicyclic structure, use of methanol as a solvent cleanly led to formation of the desired FGH ring system of $\mathbf{4 5}$. The use of a hydrogen-bonding solvent 
moderates the acidity of the system, thereby preventing formation of the destructive C35-36 enol ether. Finally, azide reduction and Teoc protection provided compound $\mathbf{4 6}$.

With the FGH rings now in place, the final challenge remaining was the formation of the azaspiro HI ring system (Scheme 8). Initial attempts to form C36 azaspiroketal using acidic media (e.g. CSA, $\mathrm{MeOH}$ ) led to extensive decomposition. Interestingly, treatment of $\mathbf{4 6}$ with $\mathrm{Yb}(\mathrm{OTf})_{3}[2 \mathrm{e}, 3 \mathrm{e}, \mathrm{g}, \mathrm{p}]$ in $\mathrm{PhMe}$ led to rapid formation (30 min, room temperature) of a single new product 47. Careful analysis by 2D NMR spectroscopy revealed that $\mathbf{4 7}$ possessed the undesired stereochemistry at $\mathrm{C} 36$. Use of extended reaction times led to formation of a second compound, compound $\mathbf{6}$; however, decomposition was a competitive pathway under these conditions. Fortunately, use of an alternate solvent (THF) at room temperature led to the desired C36 spiroaminal 6 as the major product ( $74 \%$ yield, $\mathbf{6} / \mathbf{4 7} 4: 3$ ratio). The minor product $\mathbf{4 7}$ could be recycled by resubmission to identical reaction conditions to generate the same thermodynamic 4:3 ratio. As we have previously demonstrated in our synthesis of the C1-C26 northern portion of azaspiracid-1 (1),[1h] we are able to control the stereochemical outcome during ketalization through the proper choice of conditions. We did find the formation of the unwanted spiroaminal $\mathbf{4 7}$ as the kinetic product to be surprising, as the anomerically stabilized axial orientation is typically kinetically favored as a result of a presumed lower transition-state energy. We attribute this unusual behavior to a severe steric interaction between the NTeoc group and the fused GH ring system.

In summary, an efficient synthesis of the C27-C47 southern portion (6) has been achieved in 20 steps from commercially available dichloride $\mathbf{1 6}$. The outlined approach represents the shortest route to the FGHI ring system reported to date.[2e,3e,g,p] In addition, we have demonstrated that careful selection of conditions for the ketalization steps allows control over the stereochemical outcome of the reaction. Completion of the total synthesis of azaspiracid-1 (1) will be reported in due course.

\section{Corrigendum}

Synthesis of the Southern FGHI Ring System of Azaspiracid-1 and Investigation into the Controlling Elements of C28- and C36-Ketalization

The incorrect Cambridge Crystallographic Data Center (CCDC) deposition number was listed for the X-ray crystal data of compound 22 in this Communication. The correct deposition number should be CCDC-617059. We thank Dr. Stephen Holgate (CCDC) for pointing out this error.

\section{References}

1. a Carter RG, Weldon DJ. Org. Lett 2000;2:3913-3916. [PubMed: 11101452]Carter, RG.; Weldon, DJ.; Bourland, TC. 221st National ACS Meeting; San Diego. 2001; ORG-479 c Carter RG, Graves DE. Tetrahedron Lett 2001;42:6035-6039. d Carter RG, Bourland TC, Graves DE. Org. Lett 2002;4:2177-2179. [PubMed: 12074661] e Carter RG, Graves DE, Gronemeyer MA, Tschumper GS. Org. Lett 2002;4:2181-2184. [PubMed: 12074662] f Carter RG, Bourland TC, Zhou X-T, Gronemeyer MA. Tetrahedron 2003;59:8963-8974. g Zhou X-T, Carter RG. Chem. Commun 2004:2138-2140. h Zhou X-T, Carter RG. Angew. Chem 2006;118:1819-1822.Angew. Chem. Int. Ed 2006;45:17871790.

2. a Nicolaou KC, Li Y, Uesaka N, Koftis TV, Vyskocil S, Ling T, Govindasamy M, Qian W, Bernal F, Chen DY-K. Angew. Chem 2003;115:3771-3776.Angew. Chem. Int. Ed 2003;42:3643-3648. b Nicolaou KC, Chen DY-K, Li Y, Qian W, Ling T, Vyskocil S, Koftis TV, Govindasamy M, Uesaka N. Angew. Chem 2003;115:3777-3781.Angew. Chem. Int. Ed 2003;42:3649-3653. c Nicolaou KC, Vyskocil S, Koftis TV, Yamada YMA, Ling T, Chen DY-K, Tang W, Petrovic G, Frederick MO, Satake YM. Angew. Chem 2004;116:4412-4418.Angew. Chem. Int. Ed 2004;43:4312-4318. d 
Nicolaou KC, Koftis TV, Vyskocil S, Petrovic G, Ling T, Yamada YMA, Tang W, Frederick MO. Angew. Chem 2004;116:4418-4424.Angew. Chem. Int. Ed 2004;43:4318-4324. e Nicolaou KC, Pihko PM, Bernal F, Frederick MO, Qian W, Uesaka N, Diedrichs N, Hinrichs J, Koftis TV, Loizidou E, Petrovic G, Rodriquez M, Sarlah D, Zou N. J. Am. Chem. Soc 2006;128:2244-2257. [PubMed: 16478178] f Nicolaou KC, Chen DY-K, Li Y, Uesaka N, Petrovic G, Koftis TV, Bernal F, Frederick MO, Govindasamy M, Ling T, Pihko PM, Tang W, Vyskocil S. J. Am. Chem. Soc 2006;128:22582267. [PubMed: 16478179] g Nicolaou KC, Koftis TV, Vyskocil S, Petrovic G, Tang W, Frederick MO, Chen DY-K, Li Y, Ling T, Yamada YMA. J. Am. Chem. Soc 2006;128:2859-2872. [PubMed: 16506764] h Nicolaou KC, Frederick MO, Petrovic G, Cole KP, Loizidou EZ. Angew. Chem 2006;118:2671-2677.Angew. Chem. Int. Ed 2006;45:2609-2615.

3. a Dounay AB, Forsyth CJ. Org. Lett 2001;3:975-978. [PubMed: 11277773] b Aiguade J, Hao J, Forsyth CJ. Org. Lett 2001;3:979-982. [PubMed: 11277774] c Aiguade J, Hao J, Forsyth CJ. Tetrahedron Lett 2001;42:817-820. d Hao J, Aiguade J, Forsyth CJ. Tetrahedron Lett 2001;42:821-824. e Nicolaou KC, Pihko PM, Diedrichs N, Zou N, Bernal F. Angew. Chem 2001;113:1302-1305.Angew. Chem. Int. Ed 2001;40:1262-1265.Nicolaou KC, Pihko PM, Diedrichs N, Zou N, Bernal F. Angew. Chem 2001;113:1621.ErratumAngew. Chem. Int. Ed 2001;40:1573.Buszek, KR. 221st National ACS Meeting; San Diego. 2001; ORGN-570 g Forsyth CJ, Hao J, Aiguade J. Angew. Chem 2001;113:37753779.Angew. Chem. Int. Ed 2001;40:3663-3667. h Nicolaou KC, Qian W, Bernal F, Uesaka N, Pihko PM, Hinrichs J. Angew. Chem 2001;113:4192-4195.Angew. Chem. Int. Ed 2001;40:4068-4071. i Sasaki M, Iwamuro Y, Nemoto J, Oikawa M. Tetrahedron Lett 2003;44:6199-6201.Buszek, KR.; Gibson, TS.; Reinhardt, BC.; Sunde, JR. 226th ACS National Meeting; New York. 2003; ORGN-179 k Ishikawa Y, Nishiyama S. Tetrahedron Lett 2004;45:351-354. 1 Ishikawa Y, Nishiyama S. Heterocycles 2004;63:539-565. m Ishikawa Y, Nishiyama S. Heterocycles 2004;63:885-893. n Geisler LK, Nguyen S, Forsyth CJ. Org. Lett 2004;6:4159-4162. [PubMed: 15524432] o Nguyen S, Xu J, Forsyth CJ. Tetrahedron 2006;62:5338-5346. p Oikawa M, Uehara T, Iwayama T, Sasaki M. Org. Lett 2006;8:3943-3946. [PubMed: 16928044]

4. a MacMahon T, Silke J. Harmful Algae News 1996;14:2. b Satake M, Ofuji K, Naoki H, James KJ, Furey A, McMahon T, Silke J, Yasumoto T. J. Am. Chem. Soc 1998;120:9967-9968.

5. a Mas G, Gonzalez L, Vilarrasa J. Tetrahedron Lett 2003;44:8805-8809. b Vong BG, Abraham S, Theodorkis EA. Org. Lett 2003;5:1617-1620. [PubMed: 12735735]

6 . Independently and concurrently to our effort, Nicolaou and co-workers reported the synthesis of this aldehyde. See Reference [2f].

7. a Boulet SL, Paquette LA. Synthesis 2002:895-900. b Lipshutz BH, Hackmann C. J. Org. Chem 1994;59:7437-7444.

8. Andrus MB, Meredith EL, Hicken EJ, Simmons BL, Glancey RR, Ma W. J. Org. Chem 2003;68:8162869. [PubMed: 14535799] and references therein

9. See Supporting Information for the ORTEP representation of 22. CCDC-605862 (22) contains the supplementary crystallo-graphic data for this paper. These data can be obtained free of charge from The Cambridge Crystallographic Data Centre via www.ccdc.cam.ac.uk/data_request/cif

10. a Ohtani I, Kusumi T, Kashman Y, Kakisawa H. J. Am. Chem. Soc 1991;113:4092-4096. b Dale JA, Mosher HS. J. Am. Chem. Soc 1973;95:512-519. c Sullivan GR, Dale JA, Mosher HS. J. Org. Chem 1973;38:2143-2147.

11. Nakajima N, Horita K, Abe R, Yonemitsu O. Tetrahedron Lett 1988;29:4139-4142.

12. Martin SF, Dodge JA. Tetrahedron Lett 1991;32:3017-3020. 


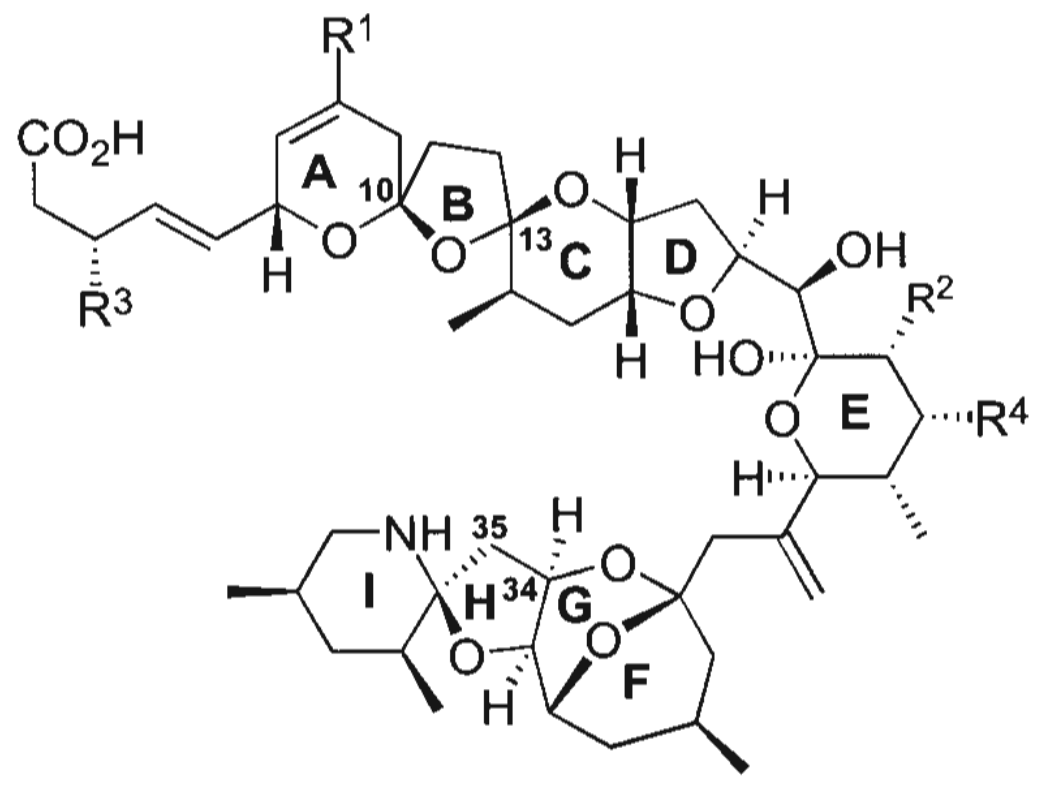

azaspiracid-1 (1): $R^{1}=H, R^{2}=M e, R^{3}=R^{4}=H$ azaspiracid-2 (2): $R^{1}=R^{2}=M e, R^{3}=R^{4}=H$ azaspiracid-3 (3): $R^{1}=R^{2}=R^{3}=R^{4}=H$ azaspiracid-4 (4): $\mathrm{R}^{1}=\mathrm{R}^{2}=\mathrm{H}, \mathrm{R}^{3}=\mathrm{OH}, \mathrm{R}^{4}=\mathrm{H}$ azaspiracid-5 (5): $R^{1}=R^{2}=R^{3}=H, R^{4}=O H$

Figure 1.

The azaspiracids. 


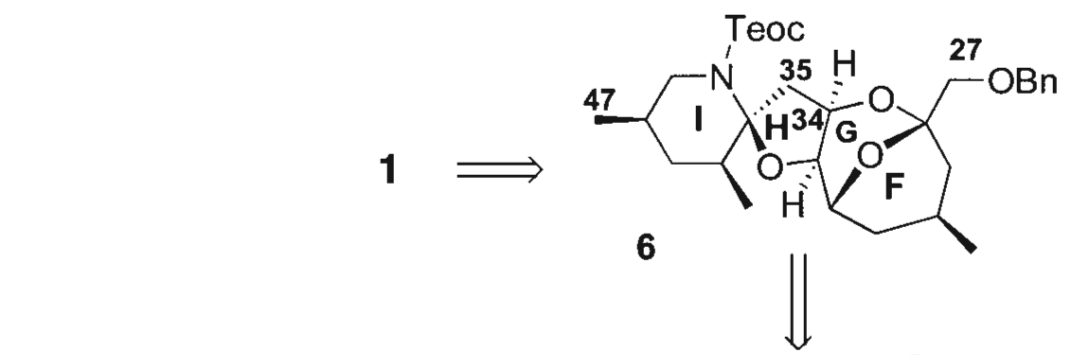<smiles>C=C=C(c1ccccc1)[C@H](O)[C@H](C)N(C)C(=O)C(C)CC(C)COCc1ccccc1</smiles>

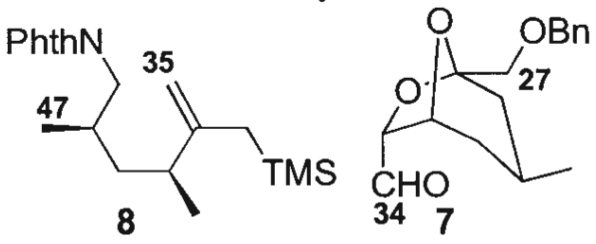
known<smiles>C/C=C/C(=O)N1CC2CCC(C)(C1)OC2=O</smiles><smiles>C=COC(=O)[C@@H]1OC(=O)[C@H]([C@H](O)CC(C)CC(=C)COCc2ccccc2)O[C@H]1C(C)OC</smiles>

Scheme 1.

Retrosynthetic analysis of azaspiracid-1 (1). Teoc $=2$-(trimethylsilyl)ethoxycarbonyl, $\mathrm{Bn}=$ benzyl, TMS = trimethylsilyl, PhthN = phthalimido. 


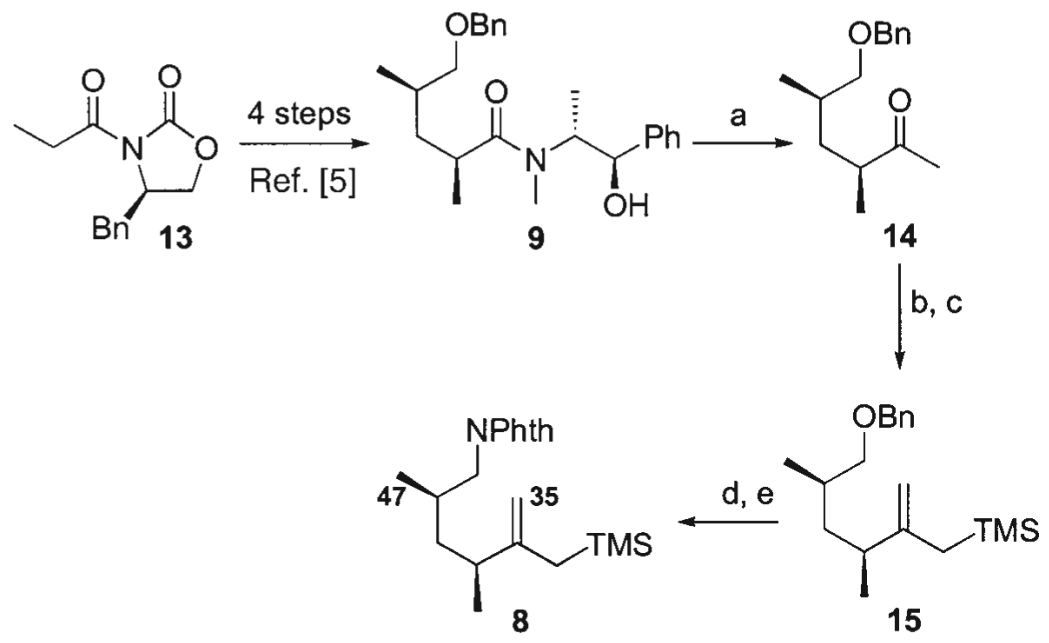

Scheme 2.

Synthesis of allyl silane 8. Reagents and conditions: a) MeLi, $\mathrm{Et}_{2} \mathrm{O}, 82 \%$; b) KHMDS, Comins' reagent, THF, 91\%; c) $\left[\mathrm{Pd}\left(\mathrm{PPh}_{3}\right)\right]_{4}, \mathrm{LiCl}, \mathrm{TMSCH}_{2} \mathrm{MgBr}, \mathrm{Et}_{2} \mathrm{O}, 77 \%$; d) $\mathrm{Na}$, naphthalene, $\mathrm{THF},-78 \rightarrow-40^{\circ} \mathrm{C}, 72 \%$; e) phthalimide, DEAD, $\mathrm{PPh}_{3}, \mathrm{THF}, 96 \%$. HMDS $=$ hexamethyldisilazide, DEAD = diethyl azodicarboxylate. 


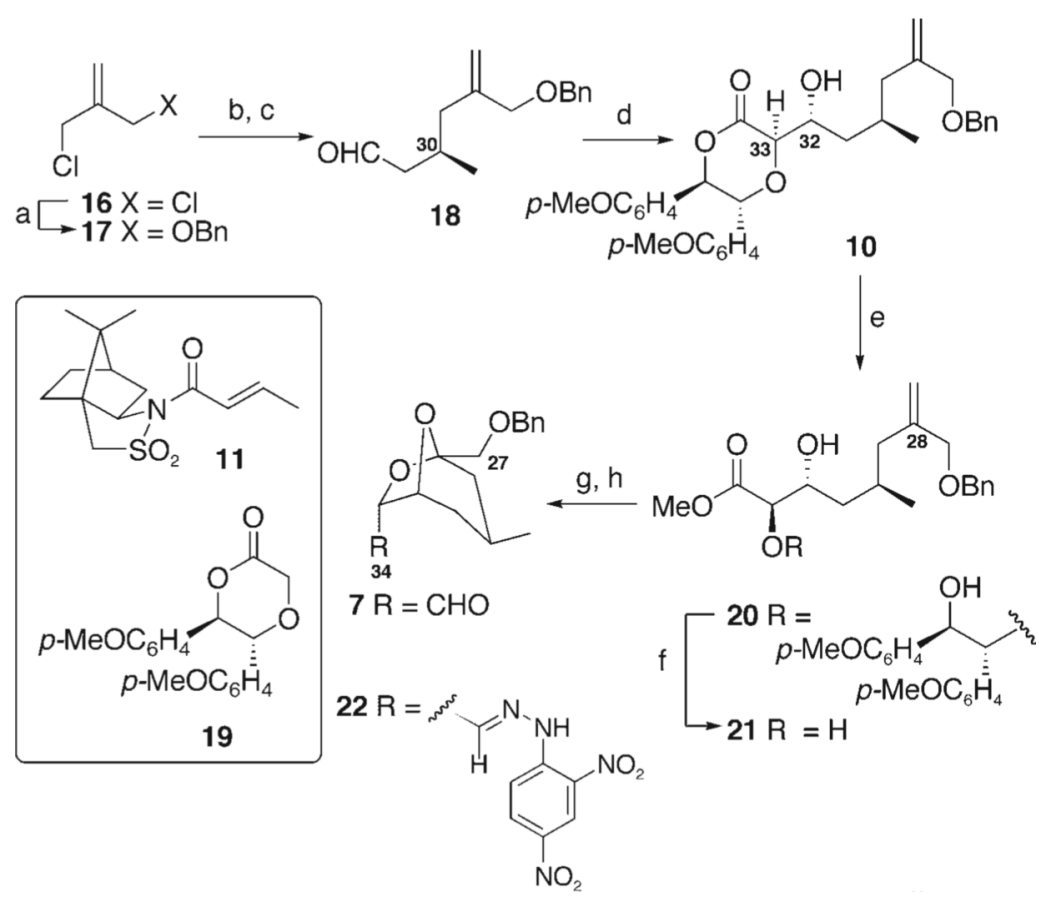

Scheme 3.

Synthesis of bicyclic aldehyde 7. Reagents and conditions: a) NaH, BnOH, THF, DMF, 77\%; b) $\mathrm{Mg}, \mathrm{BrCH}_{2} \mathrm{CH}_{2} \mathrm{Br}$, CuBr -DMS, 11, LiCl, TMSCl, THF, 90\%; c) DIBAL-H, $\mathrm{CH}_{2} \mathrm{Cl}_{2},-78^{\circ}$ $\mathrm{C}, 84 \%$; d) 19, $\left(c-\mathrm{C}_{6} \mathrm{H}_{11}\right)_{2} \mathrm{BOTf}, \mathrm{Et}_{3} \mathrm{~N}, \mathrm{CH}_{2} \mathrm{Cl}_{2} ;-78 \rightarrow-20^{\circ} \mathrm{C}, 86 \%$; e) $\mathrm{NaOMe}, \mathrm{MeOH}, 0^{\circ} \mathrm{C}$, 90\%; f) CAN, $\mathrm{MeCN} / \mathrm{H}_{2} \mathrm{O}(9: 1), 72 \%$; g) $\mathrm{O}_{3}, \mathrm{CH}_{2} \mathrm{Cl}_{2}$, DMS then Amberlyst-15, 80\%; h) DIBAL-H, $\mathrm{CH}_{2} \mathrm{Cl}_{2},-78^{\circ} \mathrm{C}, 87 \%$. DMF $=N, N$-dimethylformamide, DMS = dimethyl sulfide, DIBAL-H = diisobutylaluminum hydride, $\mathrm{OTf}=$ trifluoromethanesulfonate, $\mathrm{CAN}=$ ceric ammonium nitrate. 


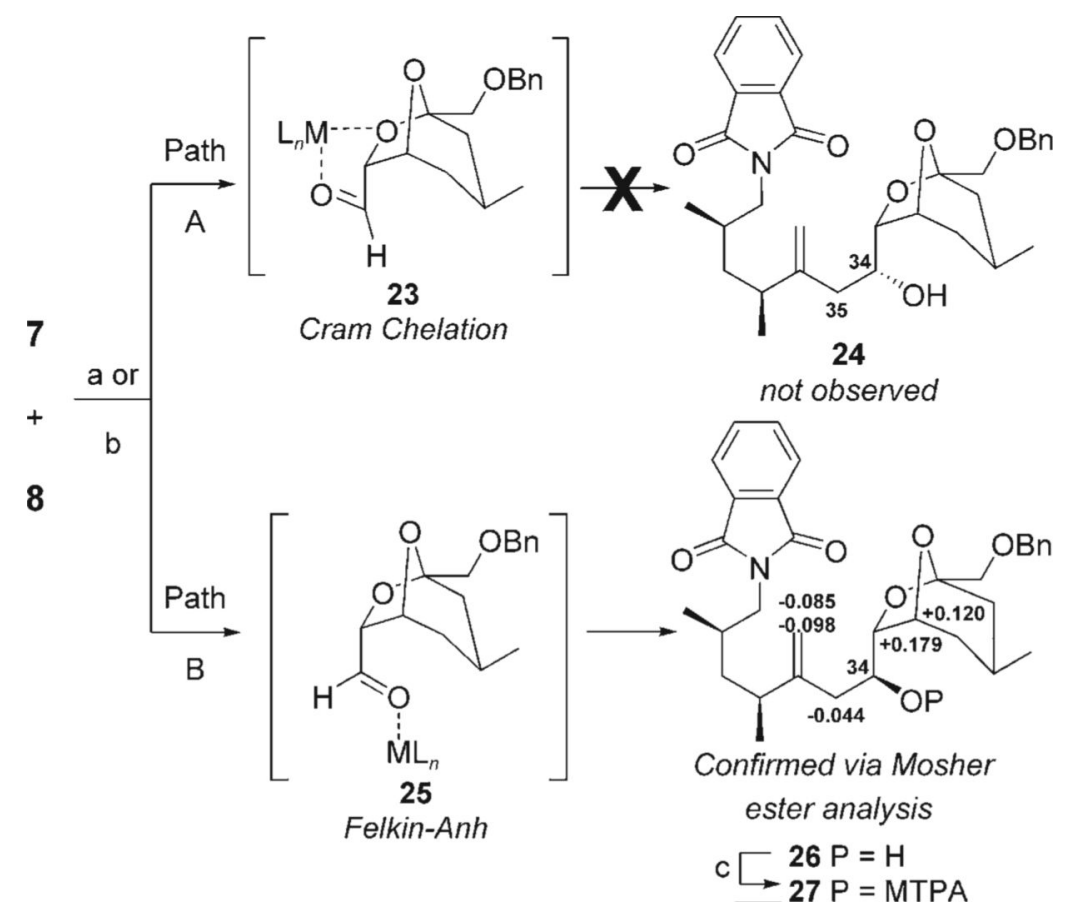

Scheme 4.

First-generation coupling. Reagents and conditions: a) $\mathrm{SnCl}_{4}, \mathrm{CH}_{2} \mathrm{Cl}_{2}, 54 \%$ (26); b) $\mathrm{BF}_{3} \cdot \mathrm{Et}_{2} \mathrm{O}, \mathrm{CH}_{2} \mathrm{Cl}_{2}, 52 \%(26)$; c) $(R) /(S)$-Mosher acid chloride, DMAP, $\mathrm{CH}_{2} \mathrm{Cl}_{2}, 45-51 \%$. Representative data points for the difference in NMR chemical shift values [ppm], that is, $\delta$ $(S)$-Mosher ester $\delta(R)$-Mosher ester, are shown for ester $27\left(400 \mathrm{MHz}, \mathrm{CDCl}_{3}\right)$. MTPA $=\alpha-$ methoxy- $\alpha$-trifluoromethylphenylacetic acid (Mosher), DMAP = 4-(dimethylamino)pyridine. 

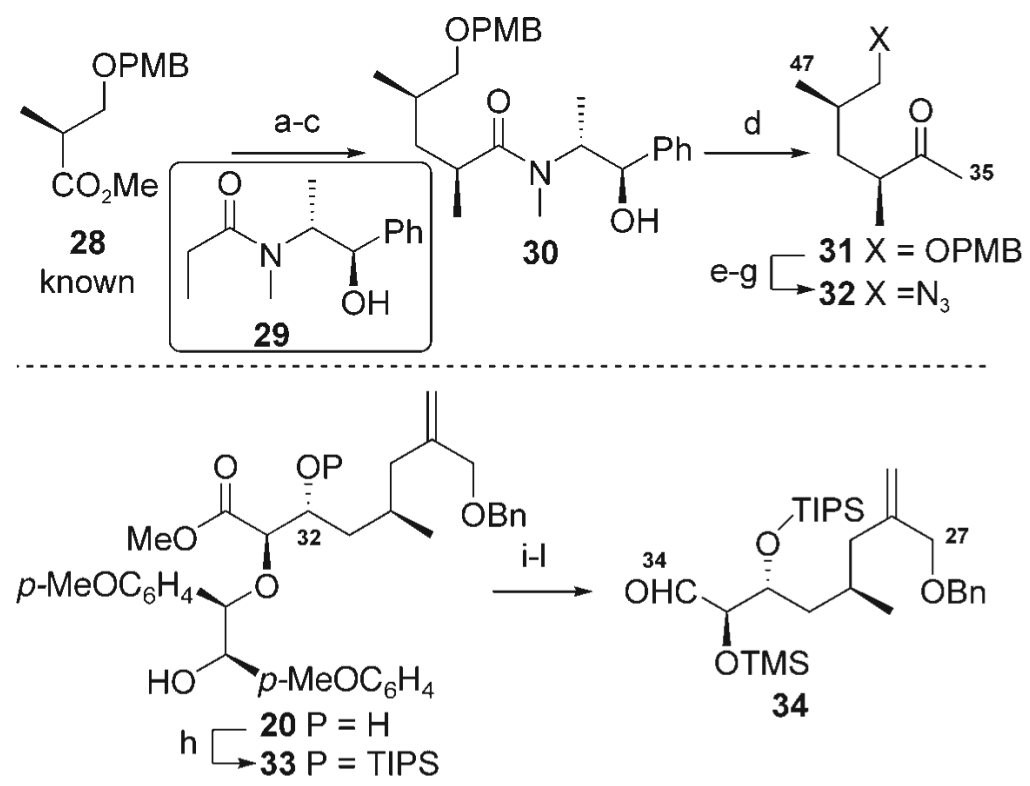

\section{Scheme 5.}

Synthesis of revised coupling partners 32 and 34. Reagents and conditions: a) $\mathrm{LiAlH}_{4}, \mathrm{Et}_{2} \mathrm{O}$, $0^{\circ} \mathrm{C}, 99 \%$; b) $\mathrm{Ph}_{3} \mathrm{P}, \mathrm{I}_{2}$, imid., $\mathrm{CH}_{2} \mathrm{Cl}_{2}, 86 \%$; c) 29, LDA, LiCl, THF, 90\%; d) MeLi, $\mathrm{Et}_{2} \mathrm{O}$, 92\%; e) DDQ, $\mathrm{CH}_{2} \mathrm{Cl}_{2}, \mathrm{H}_{2} \mathrm{O}$; f) TsCl, $\mathrm{Et}_{3} \mathrm{~N}, \mathrm{CH}_{2} \mathrm{Cl}_{2}, 64 \%$ (over 2 steps); g) $\mathrm{NaN}_{3}, \mathrm{DMF}, 92 \%$; h) TIPSOTf, 2,6-lut., $\mathrm{CH}_{2} \mathrm{Cl}_{2},-78^{\circ} \mathrm{C}, 83 \%$; i) CAN, $\mathrm{MeCN} / \mathrm{H}_{2} \mathrm{O}$ (9:1), $98 \%$; j) TMSOTf, 2,6lut., $\mathrm{CH}_{2} \mathrm{Cl}_{2},-78^{\circ} \mathrm{C}, 86 \%$; k) DIBAL- $\mathrm{H}, \mathrm{CH}_{2} \mathrm{Cl}_{2},-78^{\circ} \mathrm{C}$; l) DMP, $\mathrm{CH}_{2} \mathrm{Cl}_{2}, 76 \%$ (over 2 steps). imid. = imidazole, $\mathrm{LDA}=$ lithium diisopropylamide, $\mathrm{DDQ}=$ 2,3-dichloro-5,6-dicyano-1,4benzoquinone, Ts $=$ para-toluenesulfonyl, TIPS $=$ triisopropylsilyl, lut. = lutidine, DMP = Dess-Martin periodinane, PMB = para-methoxybenzyl. 


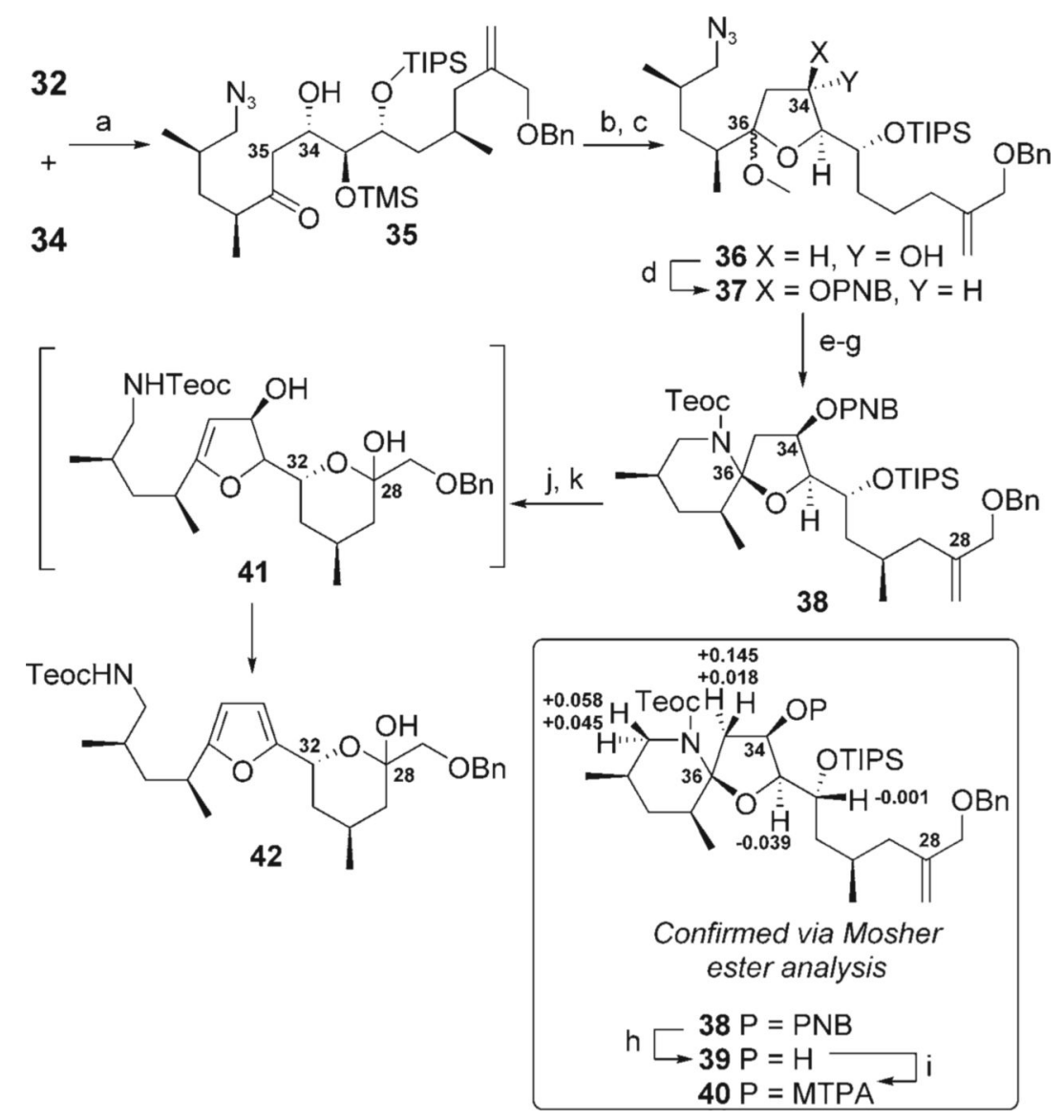

Scheme 6.

Formation of unwanted furan 42. Reagents and conditions: a) LDA, THF, $-78^{\circ} \mathrm{C}, 94 \%$; b) TBAF, HOAc, THF, 99\%; c) PPTS, MeOH, 94\%; d) $p-\mathrm{NO}_{2}-\mathrm{C}_{6} \mathrm{H}_{4} \mathrm{CO}_{2} \mathrm{H}, \mathrm{DEAD}, \mathrm{PPh}_{3}$, THF, $53 \%$; e) $\mathrm{PPh}_{3}$, THF, $\mathrm{H}_{2} \mathrm{O}$; f) Teoc-O- $\left(\mathrm{C}_{6} \mathrm{H}_{4}-p-\mathrm{NO}_{2}\right), \mathrm{Et}_{3} \mathrm{~N}$, EtOAc, $71 \%$ (over two steps); g) $\mathrm{Yb}(\mathrm{OTf})_{3}, \mathrm{MeCN}, 78 \%$; h) $\mathrm{K}_{2} \mathrm{CO}_{3}, \mathrm{MeOH}, 75 \%$; i) $(R) /(S)$-Mosher acid chloride, DMAP, $\mathrm{CH}_{2} \mathrm{Cl}_{2}, 68-72 \%$; j) TBAF, THF, $81 \%$; k) ${ }_{3}, \mathrm{CH}_{2} \mathrm{Cl}_{2},-78^{\circ} \mathrm{C}$; DMS then Amberlyst-15,

$\mathrm{CH}_{2} \mathrm{Cl}_{2}$. Representative data points for the difference in chemical shift values [ppm], that is, $\delta(S)$-Mosher ester $\delta(R)$-Mosher ester, are shown for ester $40\left(400 \mathrm{MHz}, \mathrm{CDCl}_{3}\right)$. TBAF = tetra$n$-butylammonium fluoride, PPTS = pyridinium para-toluenesulfonate, $\mathrm{PNB}=$ paranitrobenzoate. 
<smiles>C=C(CCC[C@@H](O[Pb])C1O[C@](OC)(C(C)CC(C)CN)C[C@H]1O[SbH3])Cc1ccccc1</smiles>

37

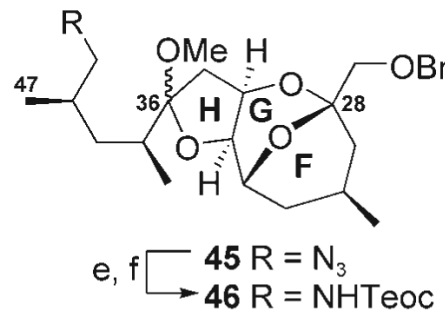

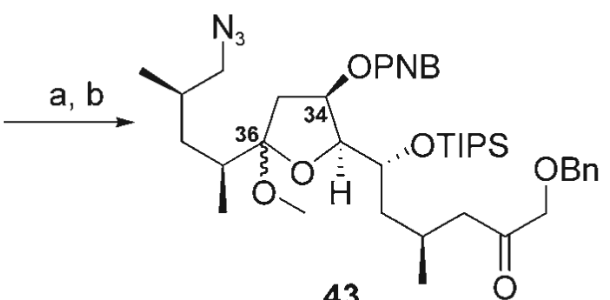

43

c

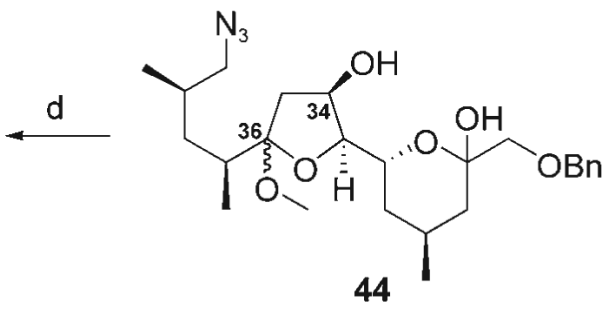

Scheme 7.

Incorporation of $\mathrm{FGH}$ ring system. Reagents and conditions: a) $\mathrm{K}_{2} \mathrm{OsO}_{4} \cdot 2 \mathrm{H}_{2} \mathrm{O}$, $\mathrm{NMO}$, acetone, $\mathrm{H}_{2} \mathrm{O}$; b) $\mathrm{NaIO}_{4}$, THF, $\mathrm{H}_{2} \mathrm{O}, 87 \%$ (over two steps); c) TBAF, THF, 85\%; d) CSA, $\mathrm{MeOH}, 79 \%$; e) $\mathrm{PPh}_{3}, \mathrm{THF}, \mathrm{H}_{2} \mathrm{O}$; f) Teoc-O- $\left(\mathrm{C}_{6} \mathrm{H}_{4}-p-\mathrm{NO}_{2}\right), \mathrm{Et}_{3} \mathrm{~N}$, EtOAc, $86 \%$ (over two steps). $\mathrm{NMO}=$ $N$-methylmorpholine- $N$-oxide, $\mathrm{CSA}=$ camphorsulfonic acid. 


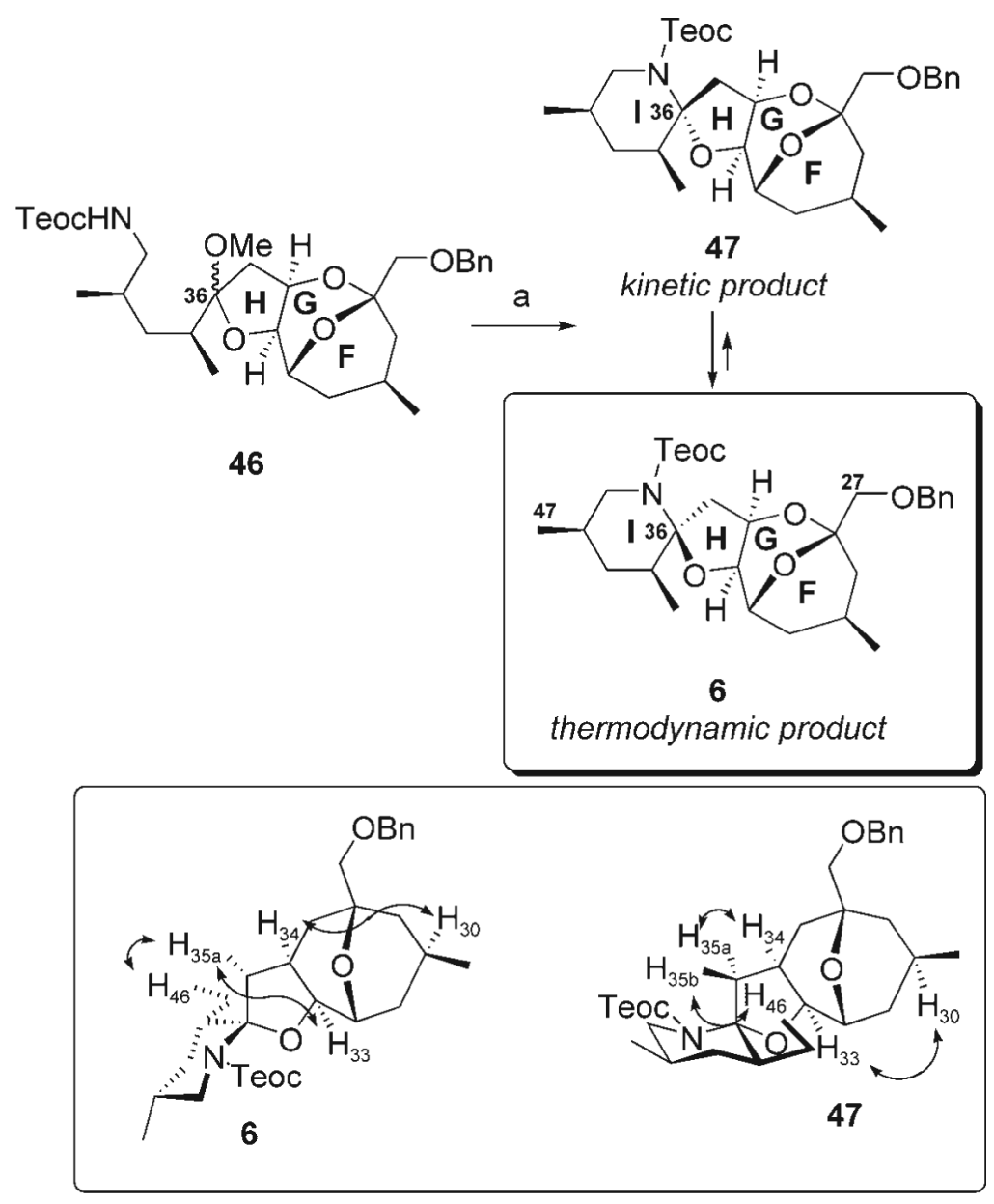

Scheme 8.

Completion of the southern fragment. Reagents and conditions: a) $\mathrm{Yb}(\mathrm{OTf})_{3}, \mathrm{THF}, 30 \mathrm{~min}$, $74 \%$ (4:3 6/47). Key NOE interactions in 6 and 47 are indicated by double-ended arrows in the lower part of the scheme. 